\title{
URBAN ENVIRONMENTAL HEALTH IN BANGLADESH SLUM: A COMPARATIVE STUDY OF TWO METROPOLITAN CITIES
}

\author{
M A Hossain ${ }^{1}$, M Moniruzzaman ${ }^{2}$ and M A Islam ${ }^{3}$
}

\begin{abstract}
This study aims to present a comparative study of socioeconomic, physical and urban environmental health condition of two metropolitan cities in Bangladesh. Slums both from Khulna and Rajshahi city were selected for this study. Although both primary and secondary data were used, this study was mainly based on primary data gathered through household questionnaire survey. In order to determine the socio-economic, physical and environmental situations, only those who were the beneficiaries of the UNICEF project were interviewed. The study finds that poor socioeconomic status and inadequacy of urban services has had an immediate effect on urban health special the slum poor in metropolitan cities in the country.
\end{abstract}

Keywords: Urban, environment, health, basic urban services, child morbidity, metropolitan city, Bangladesh

\section{INTRODUCTION}

In South Asia 39 percent of the population is living in absolute poverty, with an income of less than one US dollar a day. According to the Household Income and Expenditure Survey (HIES) 2010, the poverty rate of Bangladesh has dropped to 31.5 per cent in 2010, reflecting an 8.5 percentage point decline in the last five years (Kabir, 20111). Survey finding also shows that poverty in the rural as well as urban areas has declined to 35.2 per cent in 2010 from 43.80 per cent in 2005 and to 21.3 per cent in 2010 from 28.40 per cent in 2005 respectively. This significant decline in the poverty could be attributed to increase in the income and purchasing capacity of the people. However, the poverty levels in the country were over 70 percent in the 1970s and in 2000, this reduced to 40 per cent (Kabeer and Mahmud, 2004). Therefore it is evident that people living in hunger is dropping down which is an indication of economic development of the country. The increased remittances, use of modern agricultural input, improvements in rural infrastructure and flow of micro-credit to the poorer section of people might have played an important role in cutting down poverty in the country.

In addition to the reduction of poverty, Bangladesh has showed improvement in demographic aspects. For instance, both fertility rate and household sizes in the country has decreased after 1970 due to the government and NOGs initiatives (Hussain, 2000). The national, rural and urban household size has reduced from 5.7, 5.7 and 5.9 in 1981 to 4.9, 4.9 and 4.8 in 2001 (BBS, 1981, 1991 and 2004a). Apart from public education programme conducted by the government, NGOs and media, another factor is responsible for the declining household size which is the division of joint families in recent years because of the fragmentation of land in the rural areas (Sarker, 1993). In education sector, the country has also made progress, indicating the current adult literacy rate at 53.5 percent $^{1}$. But the corresponding rates for rural and urban areas were 46.7 percent and $67.9 \%$ percent, respectively ${ }^{2}$.

According to available statistics, the number of landless people has increased by 22 percent over the last 35 years. For example, in 1972, only 28 percent of the country's population was landless. At present this figure is as high as 50 percent (The Daily Star, May 7, 2006). The latest figures indicate that about 4.5 million of total population of Bangladesh is completely landless (BBS, 2010). A huge numbers of this landless population migrate to cities in the hope of finding a job. The informal settlement such as slums and squatters are their ultimate destination where there is dearth of civic services. In terms of housing quality, slum settlement is in deplorable state. The housing condition

\footnotetext{
${ }^{1}$ Associate Professor, Department of Geography and Environmental Studies, University of Rajshahi, Bangladesh.

${ }^{2}$ Assistant Professor, Department of Geography and Environmental Studies, University of Rajshahi, Bangladesh.

${ }^{3}$ Research Fellow, State University of Bangladesh, Dhaka.
} 
exerts the most immediate effect on the life of the low income people, especially those who are living in poor settlements. The overall urban housing quality in terms of residential density, occupancy ratio and structural conditions has all assumed critical situations in Bangladesh (Islam, 1996a). According to the census of slum area and floating population in Bangladesh, approximately 69 percent of the slum houses are made of poor construction materials (BBS, 1999). Although few indicators of development elaborated illustrate the progress of Bangladesh, the state of slum dwellers that constitutes 30-40 of the urban populations has seen not much improvement in socioeconomic status. The government interventions in terms of health and other related services are very much skewed towards the richer people.

In addition to the 1972 Stockholm Conference on the Human Environment, concerns of health have also been reflected in the Agenda 21 and in many international, regional and national forums over the decades (Goapalan, 2003). Despite such interest in the environment and human health, around 4 billion cases of diarrhea are reported in the world each year, killing some 2.2 million children under the age of five because of lack of access to adequate water and sanitation services (Franceys, 2001). In the developing countries over five million children aged between 0-14 years die every year due to various disease such as malaria, dengue, acute respiratory infections and diarrhea which are preventable and emanated from the poor environmental services (Goapalan, 2003).

Environmental health encompasses those aspects of human health that are determined by biochemical components in the natural environment and socio-economic, political factors and built environment. So it is a multi sectoral problem that involves varieties of actors from diversified sectors (Goapalan, 2003; Howze, Baldwin and Kegler, 2004). With the rapid changes in the global environment particularly in the form of burgeoning urbanization, the human health is constantly threatened. Therefore the process of urbanization could be seen as one of the major environmental changes in the world directly affecting the public health both in urban and rural areas (Stephens, 1995). The issues of urban environmental health arise because of the unrelenting process of urbanization in the developing countries. The health condition in the poor communities in the Third World cities is alarming as thousands of children still die every day from preventable disease related to the inadequate provision of water and sanitation (Bartlett, 2003).

As elsewhere in the Third World, slums and squatters in Bangladesh attracted not much attention from the public health policy makers. The health impact originated from socioeconomic status has been extensively studied focusing on mortality and morbidity (Papa, et.al, 2009). Studies on the effects of environmental factors on slum dweller's health in the context of Bangladesh are scare. Few studies have been done on urban environmental health situation in the informal settlements (Salahuddin and Islam, 1982, Hussain, Ali and Kvale, 1999). In the last two decades the researchers have paid much more attention to livelihood and quality of life. Studies have confirmed that low economic status lead to higher rate of mortality and morbidity. In both the developed and developing country, the relation between socioeconomic status and health exhibits a common pattern: the lower the socioeconomic status the poorer the health. (Singh, et. 1996; Papa et.al., 2009). Keeping in mind the above scenario the current study has set out three objectives; to study the socioeconomic situation of the study area, to outline the environmental condition and to determine the status of environmental health in the slum settlement in the two metropolitan cities in Bangladesh.

\section{Selection of the study areas}

Two divisional cities, Khulna and Rajshahi, were selected in this research for comparative study. In terms of socio-economic, administrative and legal conditions, the two cities have some in common. They also share a common history from pre-colonial to post-colonial period and there is almost no difference between their cultures. Both cities have an elected governing system - City Corporation with Mayor and Ward councilors who are elected directly by the popular vote of city dwellers. Thus, the Khulna and Rajshahi city are in many respects comparable. Moreover, both cities share a large proportion of poor population residing in the slums where the interventions of international agencies for instance UNICEF for improving urban basic services are present. Comparing slums from two cities would help to better understand the situations of slum dwellers and the differences in environmental health. Therefore, the decision to conduct a comparative study of two sets of slums from two the cities is justified. 


\section{MATERIALS AND METHODS}

Both primary and secondary data were used in this study. Detailed case studies in two cities, Khulna and Rajshahi, have been undertaken. Three slums from Khulna city and five from Rajshahi city were selected emphasizing on some socio-economic, physical, environmental service and urban health. Due to the paucity of secondary data, primary data were also collected in order to acquire knowledge about the socio-economic, physical and environmental conditions of the poor residing in the slums, who were the beneficiaries of the UNICEF project. Slum women with a household income of less than US\$ $53.85^{3}$ per month were the beneficiaries of the project. The samples were taken using simple random sampling in which total sample size was 428 households consisting 214 (total beneficiaries 703) from Rajshahi slums and 214 (total beneficiaries 703) from Khulna slums. The sample size represents 30 percent of the total population. According to the rule of thumb, this sample size sufficiently represents the overall socio-economic, physical and environmental attributes of the slums. A structured questionnaire survey was administered in the slums of two cities from July to November, 2004.. In addition to that, focus group discussions were also conducted. Each group consisted of 10 to 12 people of different profession including slum people. Another set of questionnaires also were used for interviewing key informants such as elderly people, officials both from Government organizations and non government organizations (NGOs), planners, Ward Councilors, academics and project officials who were well acquainted with the reality. Secondary sources were also extensively utilized for this study. These included books, journals, project documents, project evaluation reports, newspaper reports, unpublished reports and internet.

\section{RESULT AND DISCUSSION}

Primary data gathered through questionnaire survey has been processed, analyzed and presented in tabular form. This section focuses on the analysis part comprising of socio-economic and physical condition, environmental services and health of the studied slum people.

\section{Socio-economic and physical condition}

This section looks into the socio-economic and physical environment of the slum dwellers. To do this, some variables have been carefully selected which would reflect the real pictures of the slums. These encompasses age, education, employment, income and expenditure and housing.

\section{Age Structure}

Age structure of the respondents of both cities varies noticeably only between 31-40 and 41-50 age groups (Table.1). In Rajshahi, 39 percent of the respondents fall in the 31 - 40 year-old age group and the numbers drop sharply from the age of 40 . More than 45 percent are under the age of 30 . While 35 percent of respondents in Khulna fall in the 21-30 year-old age group, with a gradual decrease after the age of 30, excluding the age group of 50 years and above. The above 40 age group constitutes one quarter (24.76 \%) of the total respondents in Khulna, while it is 16 percent for Rajshahi.

Table 1. Ages of the Respondents

\begin{tabular}{|l|l|l|l|l|}
\hline \multirow{2}{*}{ Age Group } & Frequency & Rajshahi slum & Khulna slum & Rajshahi slum \\
\cline { 2 - 5 } & Khulna slum & 26 & 10.75 & 12.15 \\
\hline,$<20$ & 23 & 71 & 34.58 & 33.18 \\
\hline $21-30$ & 74 & 83 & 29.91 & 38.79 \\
\hline $31-40$ & 64 & 23 & 21.03 & 10.74 \\
\hline $41-50$ & 45 & 11 & 3.73 & 5.14 \\
\hline $51+$ & 8 & $\mathbf{2 1 4}$ & $\mathbf{1 0 0 . 0 0}$ & $\mathbf{1 0 0 . 0 0}$ \\
\hline Total & $\mathbf{2 1 4}$ & &
\end{tabular}

Source: Field survey, 2004

\footnotetext{
${ }^{3}$ During the field survey from July to November, 2004, the conversion rate of US\$ 1 was equivalent to 65 taka (Bangladesh currency).
} 


\section{Education}

Significant differences have been found between the education level of the respondents and literacy rates in the slums of both cities. The level of education in both cities is very low, ranges from primary to higher secondary levels. In Khulna city overall illiteracy rate is about $60 \%$ whereas in Rajshahi this rate reaches to $90 \%$. (Table.2). Figures in Rajshahi show that only 1.4 percent of respondents had a graduate-level education while in Khulna the figure was nil. Slum dwellers involvement with different NGOs at Rajshahi city might have made this difference.

Table 2. Education Status of the Respondents

\begin{tabular}{|c|c|c|c|c|}
\hline \multirow[t]{2}{*}{ Education } & \multicolumn{2}{|c|}{ Frequency } & \multicolumn{2}{|l|}{ Percent } \\
\hline & Khulna & Rajshahi & Khulna & Rajshahi \\
\hline Illiterate & 125 & 21 & 58.40 & 9.81 \\
\hline Primary & 67 & 125 & 31.30 & 58.41 \\
\hline Secondary & 19 & 60 & 8.90 & 28.04 \\
\hline Higher-secondary & 3 & 5 & 1.40 & 2.34 \\
\hline Graduate & - & 3 & - & 1.40 \\
\hline Total & 214 & 214 & 100.00 & 100.00 \\
\hline
\end{tabular}

Source: Field survey, 2004

\section{Economic condition}

Unlike education Khulna city is better than Rajshahi city in the case of employment and income factors because of scale of economics. A good number of heavy as well as light industries such as jute factories, fish factories, ship yard and processing plants, etc. are located in Khulna city which facilitate people to be employed. The present study shows that that more than half of the respondents in Khulna are found to be employed. This compares to 21 percent in Rajshahi. The average monthly household income per month and expenditure in the cities studied was 3889.60 and 3799.25 taka respectively. In Khulna city, household income and expenditure was 3898.7 and 3797.95 taka and in Rajshahi it was taka 3881.15 and taka 3801.20. Family savings were very minimal, as most of their income goes on food and non-food items (Table 3).

\section{Table 3. Monthly Family Expenditure Pattern}

\begin{tabular}{|l|c|c|}
\hline \multirow{2}{*}{ Expenditure on } & Average amount in Taka & \\
\cline { 2 - 3 } & Khulna & Rajshahi \\
\hline Food & 2767.7 & 2471.3 \\
\hline Housing & 300.95 & 395.7 \\
\hline Clothing & 188.5 & 280.15 \\
\hline Education & 173.55 & 251.55 \\
\hline Medical & 141.7 & 196.95 \\
\hline Transport & 135.2 & 3835.65 \\
\hline Total & 3707.6 & \\
\hline
\end{tabular}

Source: Field survey, 2004

\section{Housing Quality}

The most distinctive features in slum settlement is the presence of substandard housing characterized by poor structure, overcrowding and inadequate floor space. The census (BBS, 1999) indicates that 
jupries ${ }^{4}$ are more common in Khulna Statistical Metropolitan Area ${ }^{5}$ (72.43\%), while 62 percent houses in Rajshahi slums are tin-shed 6 . In terms of construction materials, survey data shows the housing situation in Khulna city is more appalling than Rajshahi (Table 4). Above 72 percent of houses in Khulna's slums are kutcha. These are slightly better than jhupri, while about 27 percent houses are semi-pucca. Pucca houses constituted less than one percent. Seventy seven percent houses, on the other hand, in Rajshahi city are semi-pucca while approximately 21 percent houses are kutcha and over two percent houses are pucca.

Table 4. Types of Housing

\begin{tabular}{|c|c|c|c|c|}
\hline \multirow[t]{2}{*}{ Types } & \multicolumn{2}{|c|}{ Frequency } & \multicolumn{2}{|l|}{ Percent } \\
\hline & $\begin{array}{l}\text { Khuln } \\
\text { a }\end{array}$ & Rajshahi & Khulna & Rajshahi \\
\hline Pucca & 1 & 5 & 0.50 & 2.30 \\
\hline Semi-pucca & 57 & 165 & 26.60 & 77.10 \\
\hline Kutcha & 155 & 44 & 72.40 & 20.60 \\
\hline Impoverished materials & 1 & 0 & 0.50 & 0.00 \\
\hline Total & 214 & 214 & 100.00 & 100.00 \\
\hline \multicolumn{5}{|l|}{ No of Rooms } \\
\hline One & 121 & 101 & 56.54 & 47.20 \\
\hline Two & 78 & 63 & 36.46 & 29.40 \\
\hline Three & 15 & 32 & 7.00 & 15.00 \\
\hline More than three & - & 18 & - & 8.40 \\
\hline Total & 214 & 214 & 100.00 & 100.00 \\
\hline \multicolumn{5}{|l|}{ Floor space $\left(\mathrm{m}^{2}\right)$} \\
\hline$<28$ & 127 & 161 & 59.35 & 75.23 \\
\hline $28-38$ & 26 & 31 & 12.15 & 14.49 \\
\hline$>38$ & 61 & 22 & 28.50 & 10.28 \\
\hline Total & 214 & 214 & 100.00 & 100.00 \\
\hline
\end{tabular}

Source: Field Survey, 2004.

The majority of households have access to electricity i.e $60.7 \%$ in Khulna and $86.1 \%$ in Rajshahi. The water supply situation is satisfactory in the slums of both cities as 100 percent of households have access to safe drinking water, although in dry season, slum people in Rajshahi has to suffer because of the fall of ground water level. In Rajshahi, 61.21 percent of households depend on the community tube well, which is installed by the city authority. About 34 percent rely on individual tube wells; while a small minority of people few people (3.3\%) have a water connection. Whereas 94 percent of slum dwellers in Khulna collect drinking water from the community tube well, and three percent depend on a neighbouring tube well. A negligible percent relies on individual tube well or a household connections.

\section{Environmental services}

\footnotetext{
${ }^{4}$ Jhupri has a ceiling of less than 4 feet high and is made of very cheap construction material like straw, bamboo, grass, leaves, polythene sheets, gunny bags etc (BBS, 1999).

${ }^{5}$ Khulna Statistical Metropolitan Area consists of Khulna City Corporation and its adjoining areas including municipality, cantonments and sub-urban areas.

${ }^{6}$ Tin-shed is a structure of normal height and its roof is made of corrugated/plain tin sheets but it does not have wall, made of bricks (BBS, 1999).
} 
The environmental health of a community is in many ways influenced by not only the socio-economic and physical conditions but also by environmental services available in the locality. The environmental status of the slums have been determined based on the state of sanitation, solid waste disposal and drainage.

\section{Sanitation}

Although the diiferecnes in ranking their priority in urban services surfaces, the survey results demonstrate that sanitation still remains as a major environmental concern. The overall sanitation condition in the slums shows a gloomy picture as demonstrated by information in table 5, Rajshahi city is better off. About five percent of slum households in Khulna have their own sanitary toilet with septic tanks, while 23 percent of the households in Rajshahi have access to a sanitary latrine. Sanitation in both cities demonstrates a varied picture, with 52 percent sharing a toilet in Khulna and eight percent in Rajshahi. In Khulna, most dwellers (above 50 \%) rely on the community toilets which were found to be very untidy and malodorous and for which they often had to wait in queue at morning times. Unclean platforms, leakage of pit latrines and septic tanks and problems of desludging have compounded the sanitation plight in the neighbourhood.

Of the three, two community toilets in the studied slums were seen to be very unhygienic and virtually unusable. But still people continued to use very unhygienic community toilets, as there were no other options. Of the three, two community toilets had separate entrances and facilities for women and men, while the other one had no separation. In Rajshahi, more than 50 percent of slum people use twin-pit or single-pit latrines while 13 percent still depend on direct pits. More than 50 percent of toilets including community toilets in the city were found to be in a tidy condition. In Rajshahi, two community toilets which provided no separation for women and men were found. In both cities no community toilets were found to be connected to the water supply which made personal hygiene and toilet-cleaning difficult or impossible.

Table 5. Sanitation Coverage in the Slums by Cities

\begin{tabular}{|l|l|l|l|l|}
\hline \multirow{2}{*}{ Toilet types } & \multicolumn{2}{|l|}{ Frequency } & \multicolumn{2}{l|}{ Percent } \\
\cline { 2 - 5 } & $\begin{array}{l}\text { Khulna } \\
\text { slum }\end{array}$ & Rajshahi slum & $\begin{array}{l}\text { Khulna } \\
\text { slum }\end{array}$ & Rajshahi slum \\
\hline Community latrine & 111 & 18 & 51.90 & 8.40 \\
\hline Twin-pit & 49 & 72 & 22.90 & 33.60 \\
\hline Single pit & 14 & 37 & 6.50 & 17.30 \\
\hline Direct pit & - & 28 & - & 13.10 \\
\hline Hanging & 23 & 2 & 10.70 & 0.90 \\
\hline Water sealed (sanitary) & 10 & 50 & 4.70 & 23.40 \\
\hline No toilet & 7 & 7 & 3.20 & 3.3 \\
\hline Total & $\mathbf{2 1 4}$ & $\mathbf{2 1 4}$ & $\mathbf{1 0 0 . 0 0}$ & $\mathbf{1 0 0 . 0 0}$ \\
\hline
\end{tabular}

Source: Field survey, 2004

\section{Waste Disposal and Drainage}

Like sanitation solid waste disposal has appeared to be one of the major environmental problems. Estimations show that more than 50 percent of urban waste in the cities of Bangladeshi remains uncollected by city authorities. Grossly inadequate or absence of waste disposal facilities in poor settlements has further aggravated the situation posing a threat to the environment. In Bangladesh's 
slums, solid waste disposal facilities are almost non existent. Few NGOs have recently been involved in collecting garbage in the poor neighbourhoods covering a small number of households.

Solid waste disposal facilities in both cities indicate an appalling condition as 62.5 percent of respondents in Rajshahi, and 72.5 percent in Khulna, respectively admitted that they had thrown waste into the river, drain, ditch or on the roadside (open dumping). Lack of consciousness, absence of trash bins in the slums and the long distances to municipal bins are considered to be the prime causes of this worst situation. Residents in few slums claim that they pay a little monthly charge for household garbage to be collected by NGOs. About eight percent households in Rajshahi and 27 percent in Khulna use municipal bins .As regards to drainage, the field survey finds that in Rajshahi, 33 per cent of households do not have drainage facilities while in Khulna only 35 percent have this access. Due to the dumping of waste into drains, lack of maintenance and irregular or no cleaning, drains have become breeding grounds for mosquitoes. Dumping waste in drains also disrupts the normal flow causing flooding and overflowing during rainy season, inundating roads and low lying areas causing havoc and environmental hazards for city dwellers. The bad smell from drains is also a major problem as claimed by slum people. Inadequate solid waste disposal and drainage is typical of Bangladesh cities, where the concerned authorities have hardly taken any measures to provide solid waste disposal and drainage facilities in the slums.

\section{Urban Environmental Health}

In this study urban environmental health includes those aspects of human health that are determined by socio-economic, political factors and built environment. Due to time limit and budgetary constraints, only the morbidity of the children is considered.

\section{Environmental health}

The foregoing discussion illustrates that lower socio-economic status, poor housing quality and inadequate environmental services are causing environmental health concerns in the slum communities. Although sanitation services have reached a good number of slum residents, still many slum dwellers are being left out. Other services such as solid waste disposal and drainage were found to be in a very poor condition. Lack of these urban environmental services coupled with other socioeconomic and housing attributes might have had an impact on the environment and public health. This study reports only morbidity among the children under the age of five as there are no reports of death caused by diseases during the survey. The rationale of considering only children lies in their susceptibility to the environmental problems and disease.

The overall health status of slum dwellers is reflected in the common diseases they suffered at the time of field survey i.e. between from July to November 2004 (Table 6). Studies on child health in slum areas show that children are more vulnerable to disease than adults. The survey results conducted by the authors confirm a higher number of diseases among children than the adults in the slum areas studied. In Khulna, of the 214 respondents, 30 percent of them are reported to have an illness within the two weeks prior to the interview. More than 20 percent of the respondents had fever followed by gastric problems (16\%), diarrhea (8\%), high blood pressure (6\%) and headache (6\%). Others diseases, which are not so prevalent, include asthma, heart problems, typhoid, skin disease and so on. Of the 214 respondents interviewed in Rajshahi slums, 32 percent were reported getting sick. Of them, 20 percent were suffering from high blood pressure, 27 percent fever, seven percent headache, seven percent gastric problems, six percent skin disease and six percent heart problems. 
Table 6. Prevalence of Morbidity among Less than 5 Years Children

\begin{tabular}{|l|l|l|l|l|}
\hline \multirow{2}{*}{ Diseases } & \multicolumn{2}{l|}{ No of sick children } & Total \\
\cline { 2 - 5 } & Khulna & Rajshahi & Frequency & \% \\
\hline Fever & $17(44.74 \%)$ & $8(22.22 \%)$ & 25 & 33.78 \\
\hline Diarrhea & $4(10.53 \%)$ & $8(22.22 \%)$ & 12 & 16.22 \\
\hline Skin disease & $2(5.26 \%)$ & $6(16.67 \%)$ & 8 & 10.81 \\
\hline Cold problem & $2(5.26)$ & $5(13.89 \%)$ & 7 & 9.46 \\
\hline Dysentery & $1(2.63 \%)$ & $1(2.78 \%$ & 2 & 2.70 \\
\hline Jaundice & $1(2.63)$ & $1(2.78 \%)$ & 2 & 2.70 \\
\hline Typhoid & $2(5.26 \%)$ & $0(0.00 \%)$ & 2 & 2.70 \\
\hline Pneumonia & $1(2.63 \%)$ & $0(0.00 \%)$ & 1 & 1.35 \\
\hline Respiratory problem & $1(2.63 \%)$ & $0(0.00 \%)$ & 1 & 1.35 \\
\hline Malnutrition & $2(5.26)$ & $0(0.00 \%)$ & 2 & 2.70 \\
\hline Mumps & $0(0.00 \%)$ & $1(2.78 \%)$ & 1 & 1.35 \\
\hline Others & $5(13.16 \%)$ & $6(16.66 \%$ & 11 & 14.86 \\
\hline Total & $\mathbf{3 8 ( 1 0 0 \% )}$ & $\mathbf{3 6}(\mathbf{1 0 0} \%)$ & $\mathbf{7 4}$ & $\mathbf{1 0 0}$ \\
\hline
\end{tabular}

Source: Field Survey, 2004.

The most common ailments afflicting children in Khulna and Rajshahi slums are fever, diarrhea, skin disease and cold problems. Adolescents in Khulna are reported, in addition, to have diseases such as typhoid, pneumonia, respiratory problems and malnutrition. Of the 115 children under five in Khulna, 38 (33\%) were reported to have an illness. The majority of children (42\%) suffer from fever followed by diarrhea (11\%), typhoid (5\%), skin disease (5\%), malnutrition, dysentery and so on. Of the 108 children in Rajshahi, 36 (33\%) are reported to have an illness. The majority of children (22\%) suffer from fever followed by diarrhea (22\%), skin disease (17\%), cold (14\%) and so on. In comparison to Rajshahi, the number of diseases among the children under five is higher in Khulna slums. Differentials in the prevalence of under five morbidity are found in the sex composition. In Khulna slums, of the 38 sick children, 21 (55\%) were boys and 17 (45\%) were girls while in Rajshahi slum the figures were 13 (36\%) and 23 (64\%) respectively out of 36 sick children. The result indicates that the morbidity rate in the slums is also higher than the city average. This finding supports the evidences of other studies indicating higher infant morbidity rates in the slum people than non-slum people (Laston et al., 1993).

The higher morbidity in the slums may be attributed to the poor health care facilities accessible to the slum dwellers. Survey findings show almost half of the slum population of the two cities seeks help from the quacks for their sickness. Nearly one third visit nearby government or private hospitals for treatment. Few go to the City Corporation health centre. Health services mostly primary health care offered to the slums are also scarce in the slums of two metropolitan cities. Although Bangladesh has achieved some progresses in health indicators of the Millennium Development Goals, still huge gap prevails in the health conditions between the rich and the poor, and also between the urban poor and the rural poor. In some instances, the deprivation of the urban poor is worse than that of the rural poor (Osman, 2009).

Abdullah, Ahmed and Rahman (1993) also reported in a study poor health services received by the slums dwellers when compared with the non-slum residents in Dhaka.

In fact, the low affordability of the slum people prevents them from getting access to the health care facilities provided either by the public or private organization. Poor health care services for the urban poor could also be explained in terms of poor health services in Bangladesh. The overall health care scenario in Bangladesh is also in a poor condition as still less than 40 percent of the population has access to the basic health care services (Abedin, 1997). The expenditure on health by the government 
is also very slim as for example in 1996-97 it amounted to about four percent of GDP and the per capita expenditure of US\$10.60 for health and family planning services (Ahmed, 2000). The previous figures on health expenditure shows that this sector is given less priority and the allocation for health is very slim. In addition, the health care service particularly in urban areas is dominated by the private commercial health facilities which poor people can not afford because of their economic hardship. In other words, the health service in Bangladesh is urban biased (Rahman and Hashem, 2000).

\section{CONCLUSION}

In developing countries, the presence of slum is very common. Practically slums have become an integral part of big cities. Poverty, unemployment, landlessness, inequality in economic development, low wages etc in the rural areas are thought to be responsible to magnetize people towards city and facilitate to erect slum neighborhood. This unabated urbanization process causes diverse troubles to the slum dwellers.

Results of the household surveys conducted in the slums in the two metropolitan cities show that the communities are almost homogenous not only by socio-economic, housing, environmental services and political status but also by environmental health standards. Some dissimilarity is also visible across housing quality, education and housing quality. Khulna features characteristics such as low literacy, poor housing, and lower educational status. These similarities and variations in the profile of the residents in slum communities might have had an influence on environmental health. Although it is very difficult to make any inference on the cause of morbidity of the slum dwellers based on a small number of socio-economic, physical and environmental variables, the inevitable consequence of poor housing environment along with inadequate urban service and its environmental impact on health is taken for granted (Sattterthwaite, 1995, Bartlett, 2003). However, low level of income, inadequate sanitation services, substandard housing and the crammed environment in the slums studied might have impacted on the environment that led to higher morbidity among the slum dwellers.

\section{REFERENCES}

Bangladesh Bureau of Statistics (1981), Population Census, Government of Bangladesh, Dhaka.

Bangladesh Bureau of Statistics (1991a) Population Census; Community Series Khulna District (Dhaka: Reproduction, Documentation and Publishing Wing, BBS).

Bangladesh Bureau of Statistics (1999), Census of Slum Areas and Floating Population, Vol. 1, October 1997, Dhaka.

Bangladesh Bureau of Statistics (2004b), Poverty Monitoring Survey Report, Government of Bangladesh, Dhaka.

Bartlett, S. (2003), "Water, Sanitation and Urban Children: The Need to Go Beyond Improved Provision”, Environment and Urbanization, Vol. 15, No. 2, pp. 57-70.

Franceys, F. (2001), Public Private Community Partnerships in Urban Services for the Poor Theme Paper: Water, Sanitation and Solid Waste, Asian Development Bank, Available at:

Gopalan, H. N. B. (2003), "Environmental Health in Developing Countries: An Overview of the Problems and Capacities” (Guest Editorial), Environmental Health Perspectives, Vol. 111, No. 9, pp. A 446-447.

Hossain, I. (2000), “Micro-Credit and Good Governance: Models of Poverty Alleviation”, Southeast Asian Journal of Social Science, Vol. 28. No.1, pp. 185-208.

Howze, E. H, Baldwin, G. T and Kegler, M. C. (2004), "Environmental Health Promotion: Bridging Traditional Environmental Health and Health Promotion”, Health Education \& Behavior, Vol. 31, No. 4, pp. 429-440.

http://www.adb.org/Documents/Events/2001/Beyond Boundaries/Theme_Paper.pdf 
Hussain, A. Ali, S. M. K. and Kvale, G (1999), "Determinants of Mortality among Children in the Urban Slums of Dhaka City, Bangladesh”, Tropical Medicine \& International Health, Vol. 4, No. 11, pp. 758-764.

Islam, N. (1996a), “The State of Urban Environment in Bangladesh”, pp. 21-31, in N. Islam (ed.), Urban Bangladesh: Geographical Studies, Dhaka University: Department of Geography and Environment.

Kabeer, N and Mahmud, S. (2004), "Globalization, Gender and Poverty: Bangladeshi Women Workers in Export and Local Markets”, Journal of International Development, Vol. 16, pp. 93-109.

Kabir, H. M.H. (2011), Poverty rate now 31.5pc, The Fiancial Express, 30 April, 2011, Dhaka, Bangladesh.

Laston, S. L, Baqui, A. H, Paljor N and Silimperi, D.R (1993), Immunization Beliefs and Coverage in Dhaka Urban Slums, Dhaka: International Centre for Diarrhoeal Disease Research (ICDDR).

Osman, F.A. (2009), “ Public Health, Urban Governance and the Poor in Bangladesh: Policy and Practice’ Asia-Pacific Development Journal, Vol. 16, No. 1, June 2009.

Papa, E. Kontodimopoulos, N. Angelos, A. Papadopoulos, A. A. and Niakas, D. (2009), “Assessing the socio-economic and demographic impact on health-related quality of life: evidence from Greece”, International Journal of Public Health, Vol. 54.

R Rahman, M. R. and Hashem, F. (2000), "The State of Health Determinants in Bangladesh", International Journal of Sociology and Social Policy, Vol. 20, No. 8, pp. 33-54.

Salahuddin, A. K. M. and Islam, M. S. (1982), "Status of Environmental Sanitation of a Slum Area in Dhaka City”, Journal of Preventive and Social Medicine, Vol, 2, pp. 63-66.

Sarker, P. C. (1993), "Decline of Traditional Family System and Reproductive Behaviuor in Rural Bangladesh”, Indian Journal of Social Sciences, Vol. 6, No. 1, pp. 65-75.

Singh, A. L, Fazal, S. Azam, F. and Rahman, A. (1996), Income, Environment and Health, Habitat International, Vol. 20, No. 1, pp, 77-91

Stephens, C. (1995), “The Urban Environment, Poverty and Health in Developing Countries”, Health Policy and Planning, Vol.10, No. 2, pp,109-121

The Daily Star (2006), “By the Numbers: The Widening Rich-Poor Gap”, The Daily Star, May 7. 